\title{
Arte, política e historia: estudio de caso de Eduardo Molinari
}

\author{
Art, Politics and History: a case study \\ of Eduardo Molinari
}

\author{
Elena Rosauro \\ Universidad Autónoma de Madrid, España \\ elena.rosauro@gmail.com
}

Resumen - El presente trabajo aborda la relación entre arte, historia y política a través del estudio de caso del artista argentino Eduardo Molinari, desde 1999 hasta la actualidad. En este artículo abordaremos el análisis de la producción artística y el discurso de Eduardo Molinari a través de cuatro ideas-fuerza: arte-política, archivodocumento, collage-montage e historia como espacio de construcción. Trataremos de definir y conceptualizar, además, el uso del documento y el archivo en la obra de Molinari, y de plantear y delimitar una serie de ideas acerca de la intervención sociopolítica a través de la práctica artística.

Palabras clave: Molinari, arte, historia, política, Argentina.

Abstract - The following paper will address the connections between art, history and politics in the work of Argentinian artist Eduardo Molinari, from 1999 to nowadays. We will address the analysis of his artistic production and written discourse through four main ideas: art-politics, archive-document, collage-montage, and history as a space of construction. We will try to define and conceptualize the use of documents and archives in Molinari's work. Also, we will question and delimit a series of ideas about socio-political interventions in artistic practices.

Keywords: Molinari, Art, History, Politics, Argentina. 


\section{INTRODUCCIÓN}

El presente trabajo aborda la relación entre arte e historia a través del estudio de caso del artista argentino Eduardo Molinari, desde 1999 hasta la actualidad. Nuestra investigación parte de dos hipótesis: en primer lugar, que la historia (como hacer científico) y el arte son prácticas que reconfiguran el pasado, el presente y sus experiencias sensibles, de manera diferente pero con ciertas concomitancias, como son: la utilización de documentos y otros vestigios del pasado, el tratamiento del tiempo y las formas de entender el continuum entre pasado y presente. Nuestra segunda hipótesis es que el trabajo artístico, a partir de la incorporación de los conceptos de documento y archivo, resignifica la relación entre historia, cultura y política.

Para estudiar la adecuación de nuestras hipótesis al escenario del arte contemporáneo, analizaremos la producción artística y el discurso de Eduardo Molinari. El corpus seleccionado consta, por un lado, de cuatro obras: El cuchillo (2000), Las mulas (2006), Tras los pasos de los hombres de maíz (2008) y Los niños de la soja (2010). Por el otro, consideraremos escritos y otras fuentes del artista: textos y publicaciones con motivo de las citadas instalaciones y un seminario que el artista dictó en el marco del ciclo Narrativas de Fuga, organizado por la Universidad Internacional de Andalucía. El título de este seminario-taller fue «¿Pueden las mulas cruzar las aguas?» y se realizó del 14 al 20 de mayo de 2010, en Sevilla.

Nuestra investigación tiene dos marcos teóricos generales: en primer lugar, un enfoque crítico a partir de las teorías del arte desarrolladas por la Escuela de Frankfurt, teniendo en cuenta que el sistema-arte alienta los impulsos autónomos de las prácticas artísticas mientras neutraliza políticamente lo que esos impulsos producen (en palabras de Theodor W. Adorno, «toda obra de arte es autónoma y, al mismo tiempo, un hecho social»). En segundo lugar, las teorías poscoloniales y sus reflexiones en torno al rechazo de las narrativas lineales sobre las naciones (Homi K. Bhabha) y sobre el hecho de que las identidades no se asumen antes de entrar en las relaciones sociales, sino dentro de ellas (Chandra T. Mohanty).

Ha sido el propio objeto de estudio el que nos ha ido sugiriendo la metodología a desarrollar: tras un primer análisis de la obra plástica y los textos del artista, un estudio del contexto social, cultural y político de la Argentina contemporánea y el análisis de la literatura seleccionada, abordamos la definición de cuatro ideasfuerza: arte-política, archivo-documento, collage-montage ${ }^{1}$ e historia como espacio de construcción. Estas, una vez definidas, nos han permitido realizar un segundo análisis crítico de la obra y el discurso de Molinari.

Nuestro texto consta de seis apartados. El primero contiene una presentación de la práctica artística de Eduardo Molinari, cuyo núcleo es el «Archivo Caminante». A partir del segundo entraremos de lleno en el estudio de nuestro objeto de investiga-

Daremos al concepto de montaje una definición más precisa dentro de la obra del argentino; y utilizaremos el término montage, para alejarlo del concepto de montaje teatral o cinematográfico y subrayar aún más su similitud con el collage, por su sentido procesual y la visibilidad de sus junturas. 
ción, y trataremos cada una de nuestras ideas-fuerza. Comenzaremos con la definición del concepto de política y su relación con el arte, idea siempre presente en su trabajo. Continuaremos con la conceptualización de los conceptos de archivo y documento, y lo que estos implican cuando se incorporan al proceso creativo. Seguidamente, estudiaremos dos técnicas utilizadas por el artista en la elaboración de sus obras: el collage y el montage. A continuación abordaremos la idea de historia como espacio de construcción, haciendo especial énfasis en tres conceptos relacionados: tiempo, memoria y narrativas. Por último, analizaremos más detalladamente el corpus de obras seleccionadas de nuestro artista.

\section{EDUARDO MOLINARI}

Mi nombre es Eduardo Molinari. Nací en Buenos Aires, Argentina. Allí vivo y trabajo. Soy artista visual, egresado de la Escuela de Bellas Artes con título de Profesor de Pintura y docente universitario en los Departamentos de Artes Visuales y Artes del Fuego del Instituto Universitario Nacional de Arte.

Caminar como práctica estética, investigar con métodos artísticos y el trabajo colectivo interdisciplinario son actividades centrales en mi labor. El cuerpo de mi obra artística se compone de dibujos, fotografías, collages, fotomontajes, películas, instalaciones, intervenciones en el espacio público y publicaciones (Eduardo Molinari, «Presentación...»s/n).

En 1999, Molinari realizó su primera visita al Archivo General de la Nación (AGN), en Buenos Aires, tras haber tomado la decisión de incorporar la historia a su práctica artística. Se acercó a él con la intención de encontrar imágenes de la historia argentina que le dieran información visual para realizar una serie de pinturas sobre las ceremonias de traspaso del poder presidencial. Acudió semanalmente al Departamento de Fotografía del Archivo durante más de medio año. Su investigación tuvo como resultado un archivo propio de unos cuatrocientos negativos sobre la historia oficial.

El Archivo General de la Nación atesora documentación escrita, fotográfica, sonora y fílmica acerca de la historia argentina, tanto producida por la administración pública como donada por particulares. La experiencia de investigación en un archivo como aquel, no especializado, hizo que a Molinari le surgieran ciertos interrogantes que han guiado desde entonces su trabajo: ¿qué es un documento?, ¿quién determina por qué una imagen se transforma en un documento?, ¿cómo se organizan esas imágenes en un archivo?, ¿cómo se construye la narración de la historia de una comunidad?

Estas preguntas, a su vez, marcaron varios quiebres en la práctica artística del argentino: la utilización de material documental, fundamentalmente fotografías, como material de trabajo, no se alejaba de su modo habitual de dibujar, pues hasta 1999 utilizaba con frecuencia tinta, acrílico y lápices junto a imágenes fotográficas recortadas de distintas publicaciones. Sin embargo, tras acudir al AGN, el artista comenzó a intervenir y dibujar sobre las fotografías de archivo, generando un cambio 
en su práctica artística de gran significado político, ya que comienza a intervenir las imágenes reconfigurando lo sensible, introduciendo sujetos y objetos nuevos, haciendo visible aquello que no lo era. El resultado de esta primera experiencia fue exhibido, de modo convencional, en la muestra El cuchillo (2000): vitrinas y cuadros en los que se enmarcaban secuencias horizontales de fotografías, como fotogramas de un filme.

Hay aun otro momento de quiebre en la práctica artística de Molinari: tras comenzar a intervenir aquellas fotografías de archivo (perdiéndole el miedo a la historia, según cuenta el propio artista), decidió también tomar sus propias fotos. Comenzó a realizar una serie de caminatas con este fin, generando su propio archivo visual. Antes de realizar cada una de sus caminatas, Molinari se interroga e investiga sobre los lugares a visitar. Una vez en movimiento:

algo empieza a suceder: los pasos para llegar y para salir de esos lugares provocan (como en los sueños) una des-jerarquización de las imágenes, dando origen a una verdadera constelación. También aparecen los sitios de encrucijada, especialmente imprevistos. Su aparición puede ser provocada por un aire, un olor, un brillo, un color, un sonido, una voz («Presentación...»s/n).

En esos sitios de encrucijada, que el artista señala en sus obras, confluyen espacios y temporalidades: mundos pasados y mundos que aún no existen. Así fue como el caminar como práctica estética, la incorporación de la historia y la concepción de la memoria como territorio pasaron al centro de su discurso y de su producción artística, dando origen a diferentes obras, instalaciones e intervenciones en el espacio público, en las que las imágenes y los documentos ya no tendrán un orden lineal o cronológico de lectura.

En el año 2001, Molinari funda el "Archivo Caminante» (AC), núcleo de toda su práctica artística posterior. Este archivo se nutre de tres fuentes: fotografías en blanco y negro, fruto de las investigaciones que, desde 1999, desarrolla en archivos públicos; fotografías propias, consecuencia de constantes caminatas; y documentación «chatarra»: libros usados, diarios, revistas, impresiones, panfletos, afiches, es decir, todo tipo de material gráfico obtenido a través de la recolección en las calles o donado por personas que conocen el trabajo del artista.

El «Archivo Caminante», que actualmente consiste en más de cincuenta cajas que contienen diversos materiales, es una obra en progreso que Molinari define como un archivo visual en torno a las relaciones existentes e imaginarias entre arte, historia y política. Es, también, un haz de interpelaciones y reflexiones críticas sobre las narrativas históricas oficiales y los procesos de momificación de la memoria social:

De la unión de estas tres materialidades visuales, de esta suerte de «nave madre», surgen los Documentos del «Archivo Caminante», que son collages, fotografías intervenidas, fotomontajes y dibujos. Estos documentos se despliegan -en mi obra artística- en distintos modos espaciales (cuadros, instalaciones, intervenciones en el espacio público). 
Podría definirlos como «documentos expandidos», siguiendo los criterios de la teórica norteamericana Rosalind Krauss («Presentación...»s/n).

Estos Documentos, posteriormente, articularán diversos nudos o constelaciones de imágenes en cada obra o instalación específica que Molinari realice. Los documentos no poseen ningún orden específico y su numeración es ficticia, puesta al azar, pues el AC no acumula para ordenar, sino que:

es un archivo de potencias para ser transportadas. La transportación (de un lugar a otro, de una generación a otra) de recuerdos / potencias que sirven para la vida [pues] el «Archivo Caminante» trabaja desde la historia, no sobre la historia: para el «Archivo Caminante» la historia no es un punto de llegada sino el lugar de partida (Ibíd.).

Este trabajo implica un esfuerzo del artista para buscar la vitalidad, remota o presente, incluso futura, de acontecimientos, recuerdos y experiencias que el argentino considera valiosas y susceptibles de transmitir. Para ello ha de localizar el hilo rojo que hilvana la trama de la historia y así habitarla:

La actividad complementaria que la búsqueda anterior propone es la indagación y experimentación de relaciones entre el cúmulo de imágenes obtenido y la palabra: la búsqueda de las narrativas deseadas para que la potencia alojada en los recuerdos se despliegue como fuerza y energía presente («Presentación...»s/n).

\section{ARTE, POLÍTICA}

Tomando la definición de política que Jacques Rancière ofrece en su libro Sobre politicas estéticas, entendemos que esta es, ante todo, la configuración de un espacio: «la política consiste en reconfigurar la división de lo sensible, en introducir sujetos y objetos nuevos, en hacer visible aquello que no lo era» (18). La estética, por su parte, es definida por el autor como una forma de aprehensión de lo sensible y, en este sentido, las prácticas y las formas de visibilidad del arte intervendrían, a su modo, en la división y reconfiguración de lo político sensible, pues también «recortan espacios y tiempos, sujetos y objetos, lo común y lo particular» (19).

Mientras política y estética reconfiguran lo sensible, el arte, afirma Rancière, expresa una experiencia espacio-temporal específica que, en su «función comunitaria», construye espacios y relaciones que resignifican territorios comunes, tanto materialmente, como simbólicamente. Podemos afirmar, entonces, que el arte es político "por el tipo de tiempo y de espacio que establece, por la manera en que divide ese tiempo y puebla ese espacio» (Rancière 17).

Esta interpretación de la política y el arte como modos de reconfiguración de lo sensible es la que guiará nuestras reflexiones sobre la práctica artística y las obras de Eduardo Molinari, pues es este modo de ser político, en su sentido más amplio y procesual, el que nos interesa aquí. Conviene diferenciarlo de la etiqueta «arte y política» que, especialmente para los artistas latinoamericanos, ha llegado 
a convertirse en un obstáculo demasiado grande a la hora de crear y exponer: en muchos casos, quien hace «arte y política» queda prácticamente fuera de cualquier otro circuito dentro del mundo del arte, pues siempre se mirará su obra a través del prisma de la denuncia social y política, o de la militancia.

El antecedente fundamental, especialmente para América Latina, de esta estrecha relación entre arte y política, lo encontramos en los últimos años de la década de los sesenta y en los primeros de los setenta (aunque solo recientemente se ha puesto esta etiqueta). En aquel momento, muchos de los artistas que realizaban obras de temática o contenido social sentían la urgencia de declarar abiertamente sus motivaciones e ideas políticas (y revolucionarias), e instaban a sus colegas a seguirlos. Por ejemplo, el Grupo de Artistas de Vanguardia participantes en el proyecto Tucumán Arde, afirmaba en una declaración hecha en noviembre de 1968: «El arte es todo lo que moviliza y agita. El arte niega radicalmente su forma de vida y dice: hagamos algo para cambiarlo» ${ }^{2}$ (cit. en Bradley y Esche 163, la traducción es nuestra). Cuatro años más tarde, en 1972, en un llamamiento a los artistas latinoamericanos desde la Casa de las Américas de La Habana, se afirmaba: «El artista latinoamericano no puede declararse a sí mismo neutral, como tampoco puede abstraerse de sus responsabilidades como ser humano por su rol de artista $^{3} »$ (Ibíd. 200, la traducción es nuestra).

A pesar de que este artículo no aborda la historia reciente del «arte político» latinoamericano, sí resulta pertinente profundizar en el hecho de que, tres décadas después de aquellas declaraciones y llamamientos, esta etiqueta hoy tiende a neutralizar la potencia de cambio que tienen determinadas prácticas artísticas.

Un ejemplo: tras el estallido de la crisis de 2001 en Argentina, todas aquellas prácticas que, a través del lenguaje artístico, trataron de borrar las fronteras entre arte y política, recibieron como respuesta esa etiqueta y, finalmente, fueron "normalizadas», neutralizadas, es decir, integradas en el sistema del arte. Como afirma el propio Eduardo Molinari: el sistema construye la categoría de «arte político» para poder clasificar cierta información y esto separa, divide, aunque pretenda aglutinar; además, presupone que cierto arte no es político. Molinari defiende la idea de que los artistas no intentan representar (conflictos, luchas, etc.) sino que, con sus obras, crean presencias.

Por otro lado, «la lógica consensual [de la política hoy] (...) es una forma activa de despolitización, de redescripción de la comunidad y de sus problemas, que impone a menudo sus límites a las voluntades militantes de los artistas» (Rancière 59). Despolitización o «tristeza política», como denuncia el Colectivo Situaciones, que se viene dando en Argentina a raíz de la «normalización» del país tras el estallido de la crisis en 2001. En nuestros días, el propio término «política» se ha despolitizado.

2 Art is all that mobilises and agitates. Art radically denies this way of life and says: let's do something to change it.

3 The Latin American artist cannot declare himself neutral, nor can he abstract his role as an artist from his duties as a man. 
Para Theodor Adorno, la importancia radical del arte se debe fundamentalmente a su capacidad de hacer visibles los conflictos que pueblan la esfera política y que suelen pasar desapercibidos entre las luchas ideológicas. Adorno abogó por el valor político del arte que guía una praxis posible, es decir, un modo de comportarse, por el que las experiencias históricas concretas son asumidas plenamente, así como también la expectativa de transformación social que se genera:

Las obras de arte están vivas en tanto que hablan, de una manera que está negada a los objetos naturales y a los sujetos que las hicieron (...). El arte niega las determinaciones impresas categorialmente a la empiria y, sin embargo, oculta en su propia sustancia algo existente empíricamente (Adorno 13-4).

Pero esta tarea es casi una utopía y «los artistas no resuelven ninguna cuestión de este tipo, por lo menos saben, desplazando los puntos de vista, invirtiendo los espacios, inventando nuevas relaciones, nuevos contactos, encarnar las cuestiones más esenciales» (Didi-Huberman, Ser cráneo 32-3), es decir, trabajan para resignificar lo sensible, nuestro espacio, y los modos en que nos relacionamos dentro de él y con él.

El artista, de este modo, es productor de nuevas relaciones entre los elementos de lo sensible. En sus prácticas y obras, encarna algunas de las cuestiones esenciales que conforman nuestra vida, pues la potencia política del arte, afirma Molinari (siguiendo a Suely Rolnik), es materializar todos los posibles que existen, permitiendo que el mundo esté en constante construcción.

\section{ARCHIVO, DOCUMENTO}

Como hemos visto, Eduardo Molinari construye el «Archivo Caminante» desde el año 2001. Lo utiliza no con el objetivo de acumular y ordenar las fotografías y el material gráfico que recopila, ni con la intención de elaborar un conocimiento sobre el material que recoge, sino como núcleo de su práctica artística y punto de partida para la creación de sus obras. El Archivo es, pues, una herramienta, pero también una elección estética de configuración de su universo creativo. Todas sus obras (fotomontajes, collages, instalaciones e intervenciones en el espacio público) surgen del "Archivo Caminante» y obtienen de él parte de su significado.

Así, Molinari es uno de los numerosos artistas que, en las últimas décadas, han elegido, bien como herramienta de trabajo, bien como estructura formal de su obra, el archivo. Esta profusión podría deberse a que la nuestra es una cultura de archivo, que da por sentado que registrar, clasificar, interpretar, guardar, exponer y narrar son acciones esenciales para el ser humano, tanto en el espacio privado como en el público (Culturas de archivo 164); es más, la cultura de archivo responde a la tendencia de construir realidad mediante su análisis, gestión, representación y control.

Por otro lado, esto potencia la fragmentación del tiempo en una serie de presentes perpetuos, congelados en documentos, que muestran el tiempo como un entretejido de nudos: pasado, presente y futuro suceden no solo de forma diacrónica sino tam- 
bién sincrónica, anudándose en una simultaneidad temporal (Hernández-Navarro 9). En este escenario, algunos artistas nos acercan la realidad sensible a la vez que exponen los artificios que la configuran mediante la incorporación de archivos y documentos a las obras de arte.

Un archivo se define como el conjunto de documentos, sean cuales sean sus formas o soportes materiales, que un individuo, una sociedad o una institución producen en el ejercicio de sus funciones o actividades, tomando en cuenta sus tres acepciones: contenido, continente y sistema de organización y gestión (Rosón 87).

Para Paul Ricoeur, el concepto archivo es sinónimo de huella y documento: son medidas no solo de la relación entre el pasado y el presente, sino también de la conexión entre la evidencia de lo ocurrido y el artificio de nuestras representaciones: «nada es en cuanto tal documento, aunque cualquier residuo del pasado sea potencialmente huella, [...] el documento no es dado simplemente [...] es buscado y encontrado» (La memoria 234). Es más, el archivo estará siempre incompleto, la huella hará siempre referencia a algo fuera de sí misma y el documento (el más legitimado como evidencia material, incluso legal) será referente y complemento de algo que existió o podría haber existido, pero que quizás ya no exista más; por tanto, siempre hay cesuras o espacios sin señalar entre el evento, su referente y su significado.

En la práctica artística de Molinari, el archivo es un espacio de construcción, una forma abierta dentro de la que estallan fronteras entre lo privado y lo público, entre ficción y documento, entre arte e historia. El archivo, pues, se concreta en su obra como marco y punto de partida para la creación, más que como concepto: el artista recopila materiales y los incluye en su archivo. Esta metodología resulta en una apropiación de las fotografías de archivo, lo cual constituye el segundo paso en el proceso creativo de Molinari. Posteriormente, a partir de la aparición de algún tema que interese al artista o le sea propuesto, los documentos del "Archivo Caminante» comenzarán a hacer visibles sus relaciones, poniendo en juego un proceso de agenciamiento por parte del archivo. Así, el artista irá articulando su discurso y exigiendo otras imágenes que completen sus obras, instalaciones o intervenciones.

Por tanto, en el seno de la práctica archivística de Molinari se darían dos procesos. En primer lugar, una apropiación de las fotografías de archivo por parte del artista, pues las incorpora al AC como documentos. Las fotografías mantienen sus identidades individuales, es decir, no se combinan en la ilusión de un todo unitario con el resto de elementos que conforman el archivo (Evans 190-2) aunque, posteriormente, Molinari hará uso de estas imágenes para tejer su discurso. En segundo lugar, se daría un proceso de agenciamiento, en el sentido deleuziano: tanto las fotografías que el artista obtiene de archivos públicos como sus propias fotografías devienen materia de archivo, puesto que son encontradas y/o tomadas para ser utilizadas 
(agenciadas) en procesos activos de collage y montage, y así construir hibridaciones con diferentes materiales para articular narrativas ${ }^{4}$.

\section{COLLAGE, MONTAGE}

El arte contemporáneo prioriza nuevos dispositivos de representación y nuevos métodos narrativos que inauguran otras formas de ver y pensar las obras; los artistas se centran en los procesos (de investigación, de creación, de exposición), en la experimentación y en la ejecución a partir de materiales y técnicas extra-artísticos, como por ejemplo, el material documental. Esto no hace sino continuar en la historia del arte una línea abierta por las vanguardias históricas a principios del siglo xx, en la que se privilegian procesos de investigación y experimentación con diferentes materiales; esa línea tendría, como puntos de referencia fundamentales: al constructivismo, con su énfasis en la experimentación con materiales en el espacio; al cubismo, con su incorporación de materiales heterogéneos a sus pinturas; al dadá, con sus obras de antiarte plagadas de objetos materiales salidos del mundo que nos rodea; al surrealismo, con sus múltiples vías de investigación sobre lo encontrado, el inconsciente y el mundo onírico; al arte pop, que se apropia de material gráfico extra-artístico; y, por fin, a los artistas de las décadas de los sesenta y setenta, con sus innumerables frentes de experimentación (especialmente en el sentido de la experiencia).

Por otro lado, una de las técnicas más utilizadas desde las vanguardias es el collage que, entonces, tenía por objeto perturbar el sentido de las obras por una invasión de fragmentos salidos de la realidad empírica y, a la vez, infligir un desmentido al sentido (Didi-Huberman, Cuando las imágenes 170). El collage, en palabras de María Luisa Ortega, maneja «con muy diferentes objetivos discursivos o expresivos, la relación dialógica entre las huellas del contexto original y la materialidad de la imagen y el nuevo contexto de resignificación en el que se inscribe» (108). Hoy, muchos artistas continúan utilizando esta técnica en sus procesos de creación, y Molinari es uno de ellos. Sin embargo, del argentino nos interesa particularmente una técnica derivada del collage: el montage.

Podemos definir el concepto de montage, pues la «actividad en que la imaginación se convierte en una técnica [...] de producir pensamiento en el ritmo incesante de las diferencias y de las relaciones» (Didi-Huberman, Cuando las imágenes toman

En Mil mesetas, Deleuze y Guattari escriben: «se pueden sacar algunas conclusiones generales sobre la naturaleza de los Agenciamientos. Según un primer eje, horizontal, un agenciamiento incluye dos segmentos, uno de contenido, otro de expresión. Por un lado es agenciamiento maquínico de cuerpos, de acciones y de pasiones, mezcla de cuerpos que actúan los unos sobre los otros; por otro, agenciamiento colectivo de enunciación, de actos y de enunciados, transformaciones incorporales que se atribuyen a los cuerpos. Pero, según un eje vertical orientado, el agenciamiento tiene por un lado partes territoriales o reterritorializadas, que lo estabilizan, y por otro, máximos de desterritorialización que lo arrastran» (11). Este párrafo nos sirve para ilustrar brevemente el complejo concepto de agenciamiento y todo lo que él implica en lingüística. De todas formas, en este artículo utilizamos este término para señalar los flujos y reflujos de las relaciones que dentro de la práctica artística de Molinari, y entre esta y el concepto de archivo, se producen. Haría falta un estudio más profundo, quizás monográfico, para definir con rigor el funcionamiento y las implicaciones del agenciamiento en el arte contemporáneo. 
posición 295), dejando al descubierto las costuras que unen los diferentes elementos en la obra resultante, rompiendo cualquier ilusión de unidad entre ellos. Los materiales que conforman un montage han sido sacados de su espacio habitual y, así, comienzan a migrar de una temporalidad a otra, subrayando las rupturas y las discontinuidades entre ellas, participando también en los procesos de apropiación y agenciamiento que señalábamos anteriormente.

A través del montage (y de sus costuras) se vuelven visibles las relaciones entre temporalidades: este, precisamente, es uno de los objetivos del trabajo de Molinari. El montage es, además, el proceso mediante el cual las relaciones entre arte, historia y política pasan de estar contenidas en el «Archivo Caminante» a estar expuestas en las instalaciones del argentino. Así pretende ofrecer una forma de conocimiento nueva, una:

heurística del montaje, [una] observación por el montaje. Atañe [...] a la «red de relaciones» $[. .$.$] que se esconde tras los acontecimientos [ya que,] ocurra lo que ocurra,$ siempre hay otra realidad detrás de la que se describe. [...] Una «red de relaciones» (...) un vasto territorio móvil, un laberinto a cielo abierto de desvíos y umbrales (DidiHuberman, Cuando las imágenes 70).

Esta heurística del montage es, quizás, la cualidad que lo distingue de otras técnicas de creación, pues implica una investigación activa con los métodos artísticos, centrando su atención en el propio proceso y en los pliegues y encrucijadas que de esta manera se van haciendo visibles, rompiendo la continuidad de las narraciones oficiales y extrayendo de ellas aquellos elementos que, remontados de forma diferente, restituyan el valor esencialmente crítico que debe tener toda historicidad.

Por tanto, puesto que el montage se hace cada vez más complejo por la heterogeneidad y la no-linealidad de los materiales que utiliza, por las relaciones que establece -relaciones entre los propios elementos utilizados, entre imágenes y significados, entre relatos previos y nuevos relatos- y por la depuración del lenguaje y las formas artísticas, esta técnica puede catalizar conocimientos nuevos, dinámicos, no codificados por la historia oficial, y dar así un paso más en la reconfiguración significativa (y política) del pasado y el presente, y de sus experiencias sensibles.

\section{HISTORIA COMO ESPACIO DE CONSTRUCCIÓN}

Volvamos por un momento a los conceptos de archivo y documento: no existe un documento objetivo o inocuo, pues «en historia, todo comienza con el gesto de separar, reunir, transformar así en "documentos» ciertos objetos repartidos de otra manera. Esta nueva repartición cultural es el primer trabajo» (De Certeau 84). Por tanto, un documento no se da sino que se busca y se constituye; un documento, afirma Ricoeur, es todo lo que pueda ser interrogado con el propósito de encontrar una información sobre el pasado, a la luz de una hipótesis de explicación y comprensión ( «Historia y memoria» 13). En la obra de Molinari son documentos, pues, tanto los materiales de archivo (fotografías y material gráfico) como sus fotografías y composiciones. 
Podemos, entonces, seguir a Foucault cuando afirma que «el documento no es el feliz instrumento de una historia que sea en sí misma y a pleno derecho memoria; la historia es una cierta manera que una sociedad tiene de dar estatuto y elaboración a una masa documental de la que no se separa» (cit. en Le Goff 236).

Consideramos aquí la historia como un espacio para la construcción, como una práctica «cuyo lugar no lo conforma un tiempo homogéneo y vacío, sino uno pleno de tiempo actual» (Benjamin 152); una práctica desde la que Molinari construye sus obras teniendo en cuenta, fundamentalmente, tres de los elementos que conforman el espacio de la historia: el tiempo, la memoria y las narrativas.

\section{EL TIEMPO Y LA MEMORIA}

Gilles Deleuze afirmaba que el fundamento del tiempo es la memoria, y esta también es el punto de partida de la historia como hacer científico aunque, a diferencia de esta última, para la memoria lo que no ha llegado a ser también forma parte de la realidad (Mate 155-62): la memoria, según Benjamin, abre expedientes que la ciencia da por archivados. Nuestra capacidad mnemónica, por tanto, nos permite repensar aquello que de otra forma sería olvidado abriendo, así, nuevos caminos al conocimiento.

En este sentido, Molinari afirma concebir la memoria como territorio, es decir, como espacio propicio para la reflexión y la reconstrucción colectiva del discurso histórico oficial. Sin embargo, no en todas sus obras nos parece que está presente esta memoria como territorio: en alguna de las instalaciones que trataremos aquí, como en Los niños de la soja (2010), encontramos fundamentalmente datos e imágenes sobre hechos históricos bastante recientes y conceptos adoptados por el artista (por ejemplo, el de semiocapitalismo, de Franco Berardi) que resultan quizás demasiado dependientes del juego discurso oficial / contradiscurso, y no permiten una incorporación plena de otros elementos o dinámicas pertenecientes al campo del arte, que podrían activar resonancias simbólicas y estarían más cercanos a esa idea de la memoria y la historia como espacio para la reflexión y la reconstrucción -sin embargo, otras instalaciones, como El cuchillo, Las mulas y Tras los pasos de los hombres de maíz permiten, a nuestro parecer, esos espacios de reflexión más dinámicos y simbólicos-.

Por otro lado, no debemos olvidar la dimensión política de la memoria colectiva (y los abusos que la acompañan), pues afecta tanto a la forma de escribir la historia como al espacio público de las sociedades occidentales, ya que lo ha invadido y se ha instalado en el imaginario colectivo, amplificada por los medios de comunicación y gestionada por los poderes públicos. Este fenómeno, en palabras de Enzo Traverso, revela un proceso de reificación del pasado, que se transforma en un objeto de consumo, al que se embellece, se neutraliza y se hace rentable (14). La historia se escribe bajo la presión de estas memorias colectivas, convirtiéndose, en ocasiones, en un instrumento y una mira de poder (Le Goff 181). Molinari, por su parte, a 
través de su discurso y de su práctica artística, pretende devolver a la historia y a la memoria (colectiva e individual) su valor como espacios para la construcción, como espacios no «momificados».

Pero no solo la memoria sufre las consecuencias de esos abusos que señalábamos; el tiempo, su fundamento, se ve afectado también, pues, en palabras de Paul Virilio, corremos el riesgo de:

perder el pasado y el futuro en favor de una "presentificación» que supone una amputación del volumen del tiempo. El tiempo [...] es volumen y profundidad del sentido, y el advenimiento de un tiempo mundial único que liquide la multiplicidad de tiempos locales es una pérdida considerable de la geografía y la historia (cit. en Berardi 185).

En esta misma línea, Manuel de Landa plantea la idea de que, aunque la naturaleza de la historia es no-lineal, "se ha vuelto uniforme y empezó a comportarse objetivamente como estructura de equilibrio lineal» ${ }^{5}$ (273, la traducción es nuestra). De Landa insta a desestratificar la realidad, porque la (narración de la) historia ha sido construida de forma lineal y equilibrada y necesitamos nuevas narrativas que la desencorseten.

Precisamente, la idea de la multiplicidad de tiempos aparece con fuerza ya en la primera instalación de Molinari, El cuchillo (2000) (Figura 1 y 2), tras incorporar la historia a su práctica artística en 1999. En esta exposición, el artista realizó en sus collages numerosos viajes de ida y vuelta desde el pasado al futuro, pasando por el presente, mostrando así su concepción del tiempo como heterocronía, concepción propia del arte y las corrientes historiográficas contemporáneas.

5 [it] had been made uniform [and] began behaving objectively as linear equilibrium structures. 

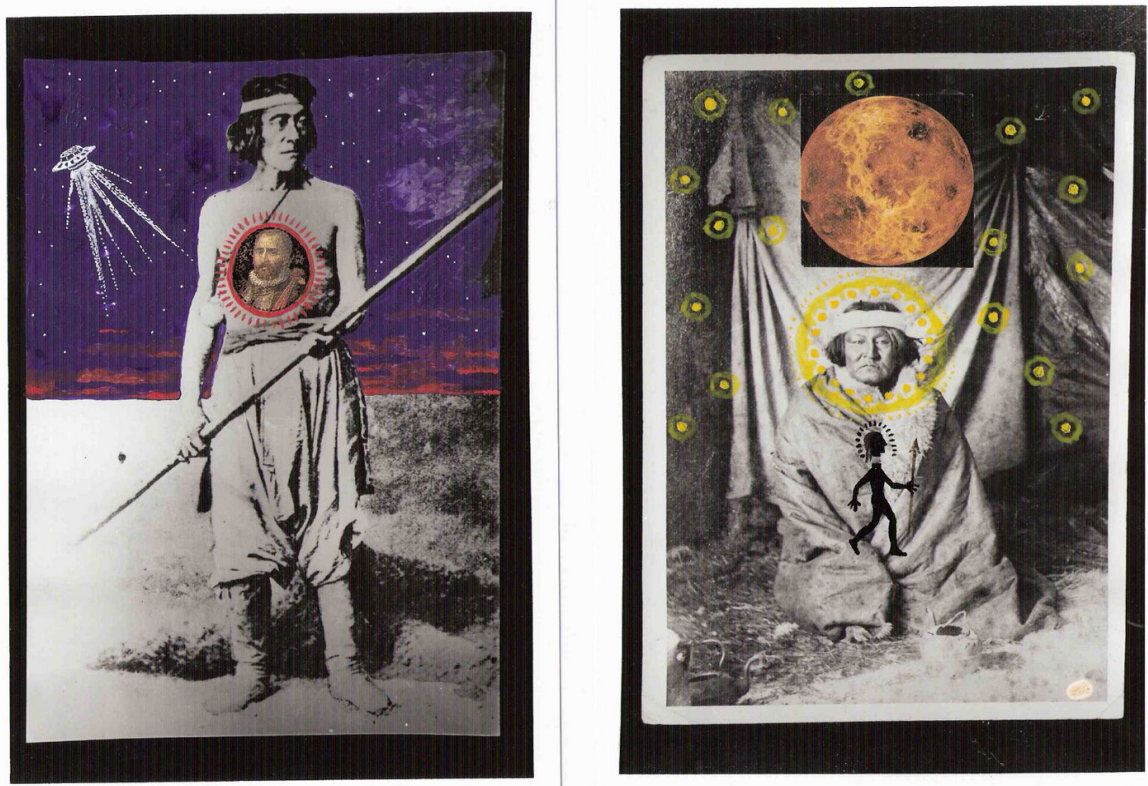

Figura 1. Eduardo Molinari. Collage de la serie La tierra y el mar. «El cuchillo», Archivo General de la Nación, Buenos Aires, 2000.

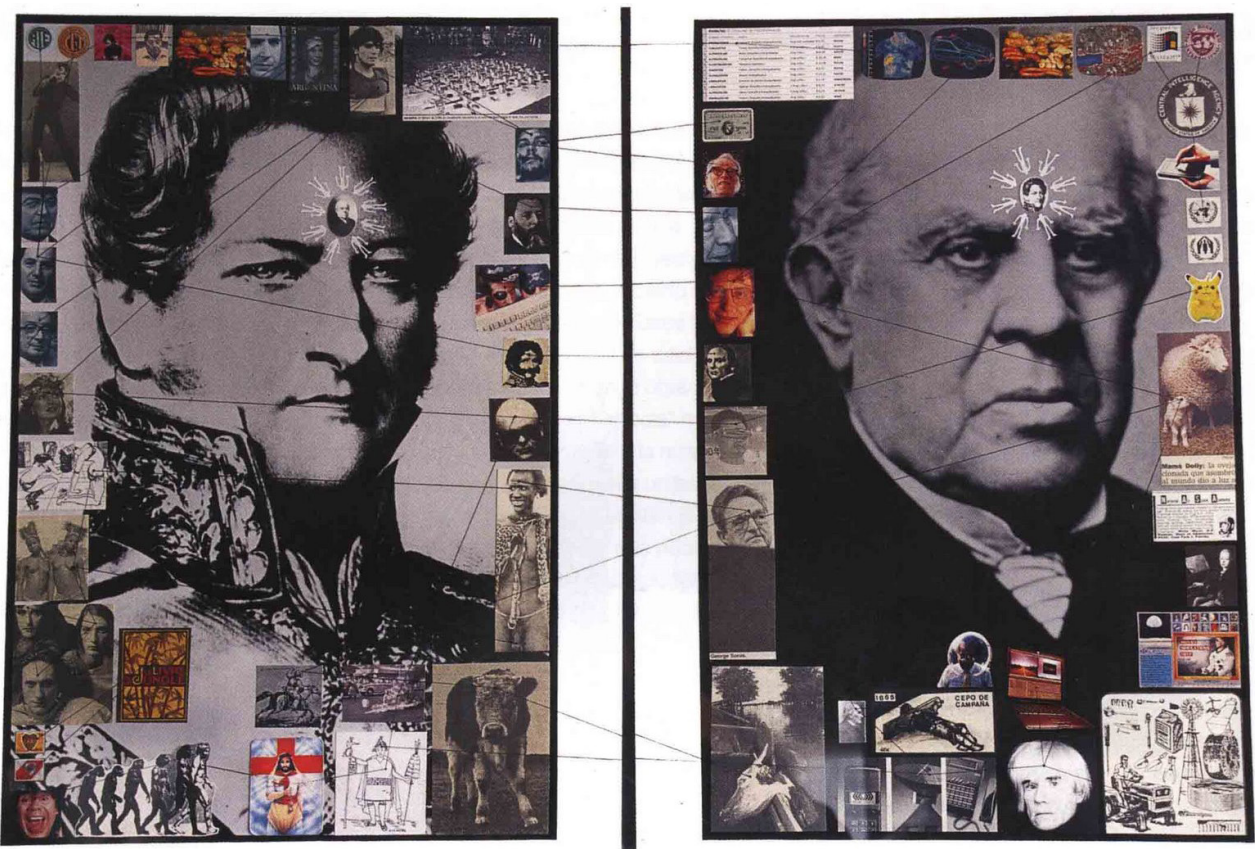

Figura 2. Eduardo Molinari. Collages de la serie Civilización o barbarie, «El cuchillo», Archivo General de la Nación, Buenos Aires, 2000. 
La referencialidad histórica de las fotografías y grabados que conforman los collages expuestos en El cuchillo es muy diversa: el artista apela a los intensos antagonismos, políticos y sociales, que han poblado la historia argentina para hacer visibles, por un lado, las luchas de poder y, por otro, las utopías que han ido moldeando la «búsqueda del ser nacional». El título de la muestra hace referencia al libro de Ezequiel Martínez Estrada Radiografía de la pampa, en el que se plantea la importancia que el cuchillo tuvo para los gauchos, como excusa para abordar un análisis de la identidad de los argentinos. Molinari explica, en el texto que preparó para esta exposición, que el cuchillo es:

síntesis de las herramientas que el hombre utiliza desde sus orígenes, [y] a través de su dualidad como utensilio para tareas propias de tiempos de paz y de su eventual uso como arma, el cuchillo otorga especial identidad a los seres que depuran la destreza en su manejo. Arma emblemática del gaucho, y luego del guapo, "por su tamaño, el cuchillo impide que nadie tercie en la lucha...». Yo y el otro, bandos, facciones, cuerpo a cuerpo. En la sostenida búsqueda de nosotros mismos y por ello de nuestro lugar en el mundo, los argentinos caminamos repetidas veces por el filo del cuchillo (Molinari, texto para El cuchillo s/n).

Mediante el collage, el artista realiza en esta exposición una migración de sentido sobre la referencialidad que cada elemento ofrece: nos han contado la historia argentina -la historia oficial argentina- y reconocemos las imágenes fotográficas de archivo, pero los collages interfieren en esa narrativa hegemónica para ofrecernos una mirada diferente, que trae al primer plano las problemáticas relaciones entre el poder y la violencia, y cómo estas han sido y son centrales en el relato histórico. De esta manera, las narrativas que el artista pone en juego en cada obra toman forma en el presente como fragmentos de otros tiempos (pues son, como sabemos, en su mayoría, documentos, fotografías de archivo) y fomentan en el espectador un ejercicio de repensar la historia y sus lazos con el tiempo actual.

\section{LAS NARRATIVAS}

La función narrativa pierde sus functores, el gran héroe, los grandes peligros, los grandes periplos y el gran propósito. Se dispersa en nubes de elementos lingüísticos narrativos, etc., cada uno de ellos vehiculando consigo valencias pragmáticas sui generis (Lyotard 10).

Los modos de elaborar o narrar la historia influyen en, y se ven influidos por, los modos de recoger o modificar las experiencias históricas; la investigación resulta indisociable de la narración. De igual manera, en la práctica artística de Eduardo Molinari es tan importante el concepto de investigación con métodos artísticos (visitas a archivos, caminar como práctica estética, lecturas especializadas sobre arte, historia y política, etc.) como la propia elaboración o montage de las obras. 
En ellas, el artista pone en diálogo imágenes y hechos históricos, lugares y tiempos, saberes y competencias, es decir, narraciones múltiples y no solo enunciados denotativos y prescriptivos, propios de un saber narrativo unitario (Lyotard 61). Por supuesto, las narrativas no solo son escriturarias, existen otros lenguajes capaces de expresar y transmitir información y conocimiento a través de signos no-alfabéticos. En este sentido, Walter Mignolo afirma, tras estudiar el quipu andino, que:

El reconocimiento de alfabetizaciones alternativas no es solo un tema interesante, sino, además, un indicio de vías alternativas de conocimiento que pueden menoscabar nuestra actual concepción del conocimiento, entendimiento, y las políticas de búsquedas intelectuales ${ }^{6}$ (310, la traducción es nuestra).

Las narrativas sobre la historia no deberían escapar a esta mirada más amplia, puesto que lo que el historiador produce no es una representación objetiva de esa realidad, sino, más bien, una construcción significativa de ella (Cabrera 124), una reorganización del pasado y del presente, como también el lenguaje del arte realiza. Pero, en la tradición cultural occidental, y muy especialmente desde el Renacimiento, la escritura se ha ido distanciando, cada vez más, de la pintura o el dibujo. Sin embargo, prácticas como la del quipu «(...) desafiaron un concepto de escritura que, en la Europa Renacentista, se estaba creando a través de la experiencia del alfabeto ${ }^{7}$ (Mignolo 295, la traducción es nuestra). Conviene subrayar en este punto, junto con Traverso, que:

la estructura de la Historia es una práctica discursiva que incorpora siempre una parte de ideología, de representaciones y de códigos literarios heredados, que se refractan en el itinerario individual de un autor (...) [luego] el historiador no puede esquivar el problema de la «puesta en texto» de su reconstrucción del pasado (57-9).

Las configuraciones narrativas y retóricas, por tanto, estructuran al autor y a su lector mediante un doble papel: como mediadoras de lo real histórico y como filtros que opacan la pretendida transparencia de esas mediaciones. Pero las pruebas documentales, como ya señalamos, tampoco son inocuas.

Molinari considera la historia y la memoria como un espacio para la construcción y como punto de partida para la creación, dando lugar a una serie de reflexiones ligadas a la relación entre los modos narrativos de las imágenes históricas, la historia misma y la figura del historiador. Él mismo se pregunta:

¿cómo relatar en imágenes una experiencia singular o colectiva valiosa para la comunidad?, ¿qué subjetividad o historiador es deseable hoy para narrar estas experiencias?, ¿cuál sería el lenguaje adecuado para que las potencias alojadas en el pasado (cercano o remoto) no pierdan su capacidad transformadora? («Presentación...»s/n).

\footnotetext{
6 The recognition of alternative literacies is not only an interesting subject matter but an important indication of alternative ways of knowing which may impinge on our current conceptions of knowledge, understanding, and the politics of intellectual inquiry.

7 (...) challenged a concept of writing that, in the European Renaissance, was being established on the experience of the alphabet.
} 


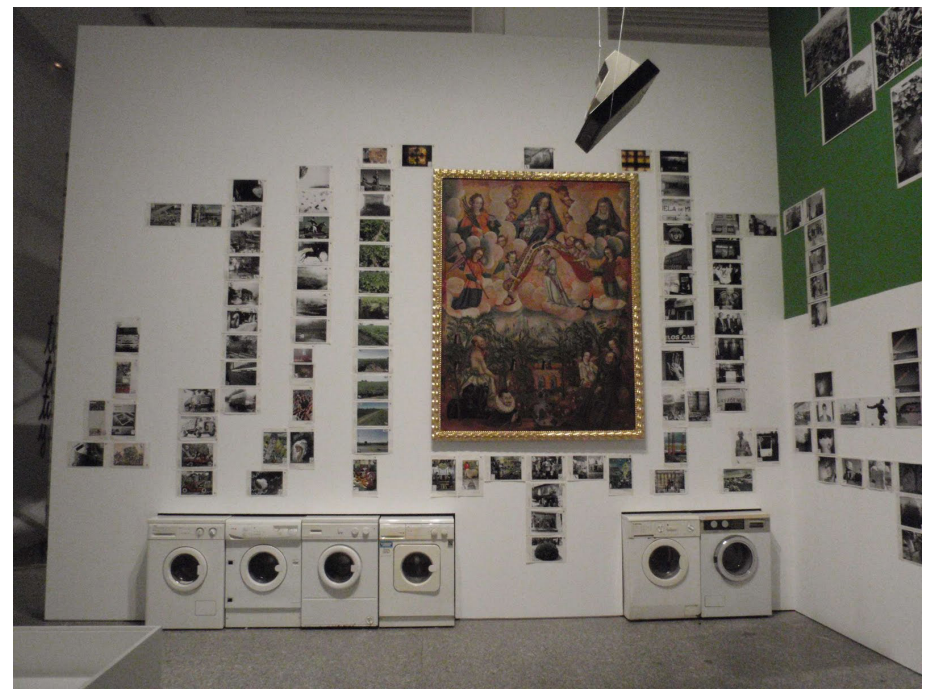

Figura 3. Eduardo Molinari. «Los niños de la soja». Vista parcial de la instalación. Museo Nacional Centro de Arte Reina Sofía, Madrid, 2010.

El artista parte del supuesto de que toda narración es fruto de una construcción colectiva, de un haz de relatos que se entrelazan. La historia y la memoria no son una excepción pues no constituyen una narración unitaria; es más: quien rechace participar en esta construcción colectiva que es la historia, afirma el argentino, deja en el territorio un agujero, una huella visible de su ausencia:

Mi práctica artística se desarrolla al interior de un pliegue en el cual se borronean fronteras impermeables entre lo singular y lo colectivo. El «Archivo Caminante» no es una obra individual ni individualista, solo es posible a partir de una experiencia y un hacer colectivo. No es mi historia, no es tu historia: es nuestra historia («Presentación...»s/n).

Pero cabe preguntarse: ¿qué memoria, qué historia y qué narrativas desencadena y construye Molinari a través de su obra?, ¿es solamente una historia o una memoria individual y subjetiva o realmente, como pretende, interfiere en nuestra historia? Resulta difícil responder aquí estas preguntas, sin embargo, es pertinente subrayar que, a través del «Archivo Caminante», el discurso, las narrativas y las imágenes de Molinari cobran fuerza por el hecho de trabajar siempre desde el AC, con formatos de obra similares (aunque los espacios expositivos cambien) y contenidos también muy relacionados entre sí (generalmente aborda conflictos políticos y sociales a lo largo de la historia argentina, reclamando juego político limpio y justicia). Es así como el «Archivo Caminante» adquiere fuerza a través del desenmascaramiento de «las ilusiones y mistificaciones que constituyen la esencia real de esta civilización, para que finalmente la diferencia se exprese, con una fuerza en sí misma repetitiva, llena de cólera, capaz de introducir la más extraña selección» (Deleuze, Diferencia y repetición 432). 


\section{EL CORPUS}

Llegados a este punto, nos centraremos en realizar una lectura crítica del corpus de obras seleccionado para nuestra investigación, con el objetivo de mostrar las fortalezas y debilidades tanto del aparato teórico como de la práctica artística de Eduardo Molinari. Fundamentalmente analizaremos la instalación titulada Los niños de la soja, exhibida recientemente en la exposición colectiva Principio Potosí (Museo Nacional Centro de Arte Reina Sofía, Madrid, 2010) (Figura 3), pero siempre poniéndola en relación con el resto de obras de nuestro corpus.

El espacio que conforma Los niños de la soja rodea al espectador, pues se trata de un rectángulo cerrado salvo por dos huecos: la entrada y la salida; además, la instalación se encuentra dentro de una gran sala en la que se despliegan el resto de obras de los artistas participantes en la muestra colectiva. Molinari despliega documentos del «Archivo Caminante» (fundamentalmente fotografías en blanco y negro) por las paredes del rectángulo hasta una altura considerable, lo que dificulta una visión cómoda por parte del espectador, obligándolo a esforzarse para poder leer las imágenes expuestas.

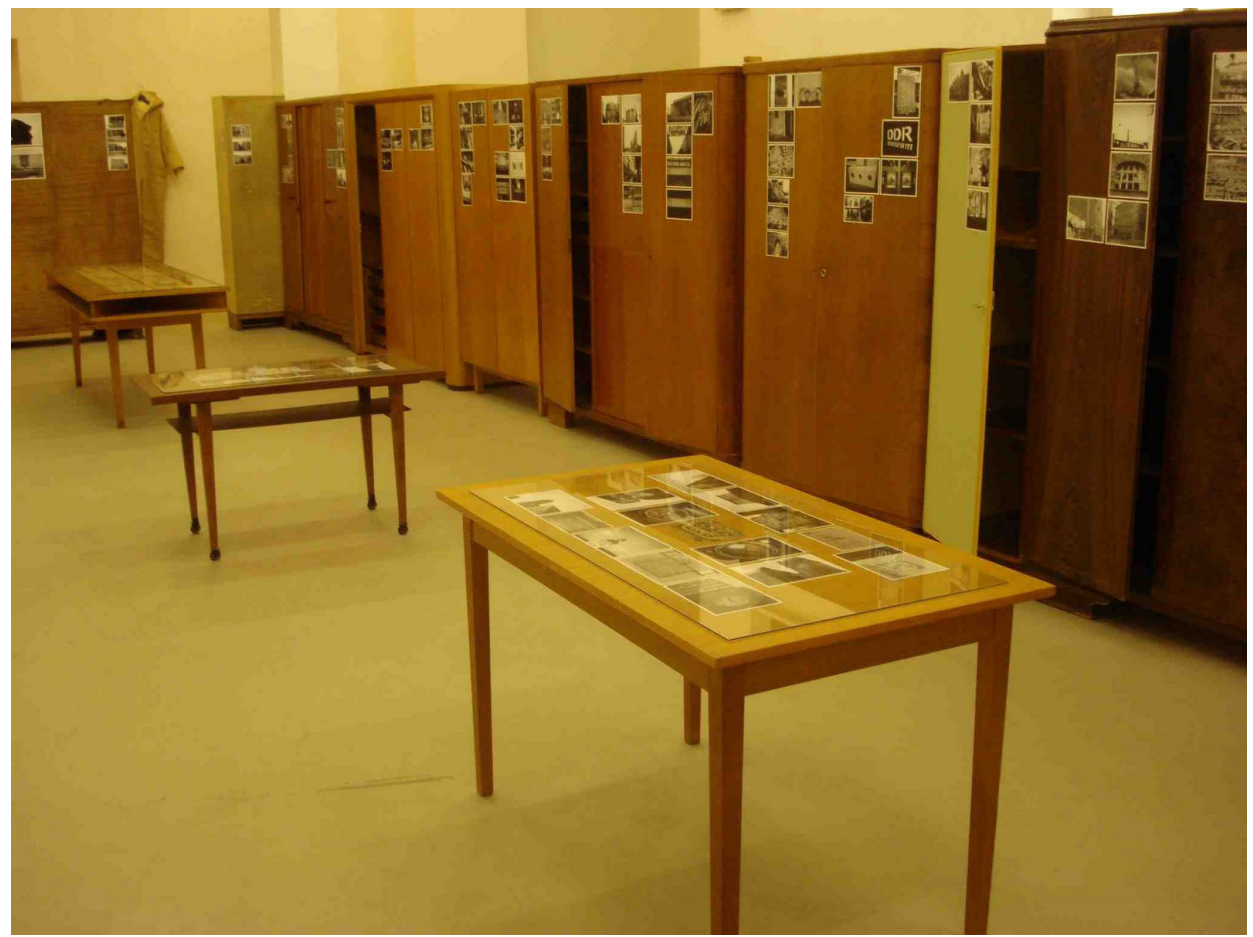

Figura 4. Eduardo Molinari. «Tras los pasos de los hombres de maíz». Vista parcial de la instalación. Galería Weltecho, Chemnitz, Alemania, 2008. 
En esta obra, como en Tras los pasos de los hombres de maíz (Galería Weltecho, Chemnitz, Alemania, 2008) (Figura 4), es evidente la importancia que la investigación sobre el tema elegido -los efectos, esencialmente negativos, del incremento de los cultivos de soja transgénica en Argentina- ha tenido en el proceso creativo: las fotografías y collages que componen esta obra (junto con otros materiales que completan el montage -seis lavadoras y una caja registradora-) hacen referencia explícita a la «sojización» de los campos y la economía argentinos.

Como señalábamos anteriormente, en esta instalación existe, a nuestro parecer, demasiada dependencia de datos históricos y periodísticos y de conceptos adoptados por el artista, tanto de la jerga de la investigación (trans)genética (conceptos como recombinación, transgen, etc.), como de autores cercanos a la militancia política y sindical (como Franco Berardi y su semiocapitalismo, o Santiago López Petit y su fascismo postmoderno); esto no deja lugar a demasiados juegos del lenguaje artístico pues el discurso (y el texto autoeditado por el artista con motivo de la exposición) se «come» a la obra. Pensamos que no se da aquí, por tanto, la posibilidad de un juego simbólico a través del collage o el montage, como sí pensamos que ocurre en las otras tres obras seleccionadas para nuestro corpus, pues el significado de la instalación viene fundamentalmente dado por el discurso escrito del artista y al espectador no le queda demasiado espacio para realizar activamente su propia interpretación. Quizás esto se deba a la dificultad, que el propio artista denuncia, de penetrar en el mundo del cultivo de la soja, pues:

a diferencia de otras experiencias en mi práctica caminante, en esta ocasión la temporalidad del presente, casi imperceptible como las gotas finas del glifosato pulverizado sobre las poblaciones sojeras, se pegaba hasta cubrir todo intento de habitar el pasado o el futuro (Molinari, Los niños de la soja 83).

El artista trata de activar en el espacio de su obra un diálogo entre los diferentes elementos que la componen y los hechos que hace presentes: despliega relatos que se entrecruzan y tienen como escenarios desde los campos de soja o las vastas extensiones de terreno explotadas durante la época colonial a los despachos de los gobernantes neoliberales. Sin embargo, el fuerte discurso de denuncia del colonialismo y del neoliberalismo que funciona como punto de partida para la obra de Molinari y articula la instalación (y también, en general, la muestra colectiva) se impone sobre cualquier otro intento de interpretación (hasta cierto punto) alternativo. Y es que:

las luchas sociales, las relaciones de clase, dejan su huella en la estructura de las obras de arte; frente a esto, las posiciones políticas que las obras de arte adoptan son epifenómenos que por lo general perjudican a la elaboración de las obras de arte y a su propio contenido de verdad social. La convicción sirve de poco (Adorno 306).

Esto ocurre efectivamente, si la convicción no deja espacio para la resignificación de las formas y las relaciones propuestas por el arte que cada espectador individual pueda realizar. Por el contrario, en Tras los pasos de los hombres de maiz (2008), 
las relaciones entre los distintos materiales que componen la instalación (fotografías, collages, dibujos y mobiliario) son más complejas: la referencialidad fundamental de las imágenes apunta, por primera vez, más hacia el futuro y la capacidad de imaginar del artista que hacia la historia y el pasado. Tanto la instalación como el texto que la acompaña están plagados de referencias a personajes míticos (como los hombres de maíz del Popol Vuh) y a personajes ficticios (el Hombre Orwo, creado por Molinari, cuyo cuerpo se compone de fragmentos de celuloide). Estos personajes, junto con otros históricos (como Marx y Eva Perón), parecen tender puentes entre el presente y el futuro de la sociedad en que vivimos. Aquí, lo que opera a través el montage es «un desplazamiento de las relaciones entre las funciones significante, imaginativa y narrativa que conforman una realidad» (Rancière 81) que permite al espectador introducirse en esas relaciones y aportar nuevos significados. Al mismo tiempo, se nos hace visible fundamentalmente un proceso de búsqueda, quizás la del propio Molinari como artista.

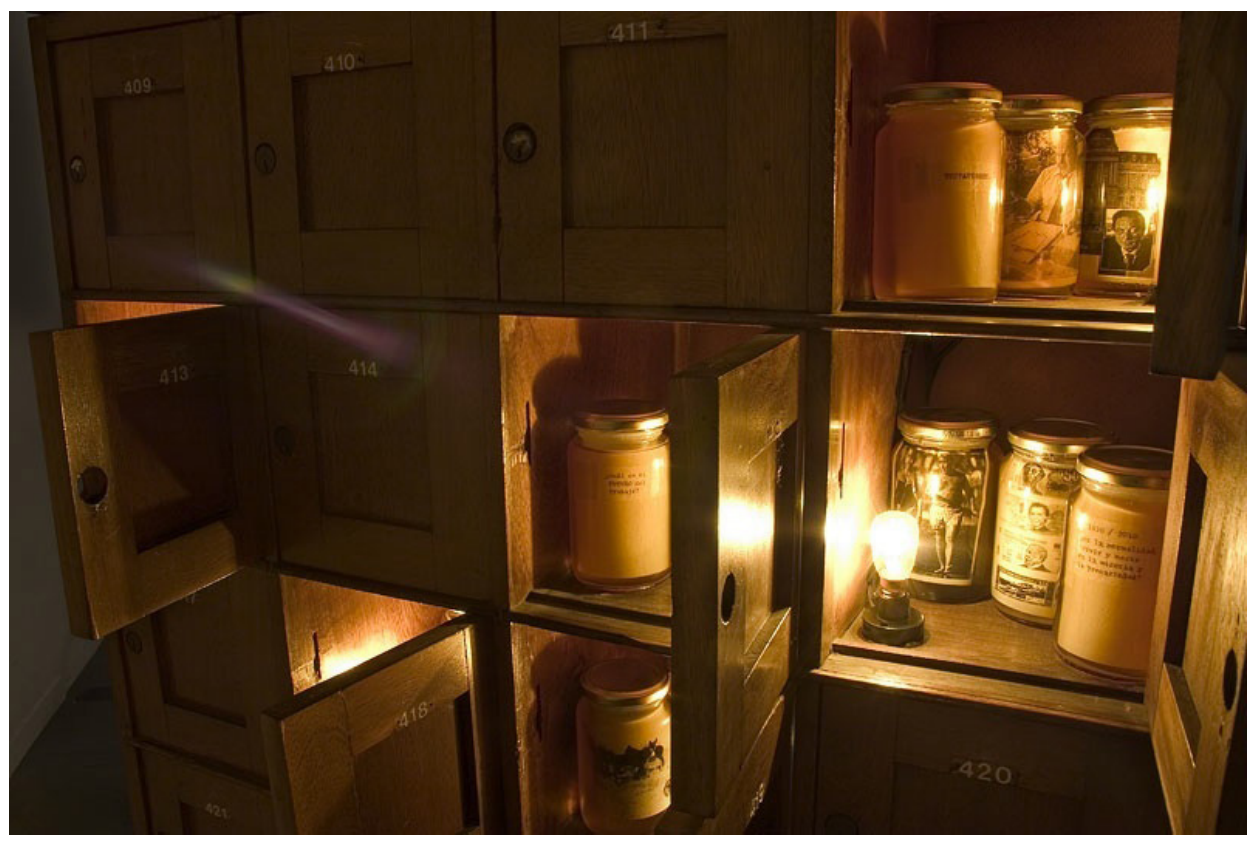

Figura 5. Eduardo Molinari. «Las mulas». Vista parcial de la instalación. Estudio Abierto, Correo central, Buenos Aires, 2006.

En la instalación titulada Las mulas (Estudio Abierto, Correo Central, Buenos Aires, Argentina, 2006) (Figura 5) el montage envuelve a quien se acerque a él (por la materialidad de la luz tenue y la miel, pues sumergidas en ese fluido se muestran fotografías de archivo), y las relaciones entre los elementos que componen la instalación adquieren protagonismo: las fotografías migran de sentido en contacto con la miel y la luz, rodeadas de cierta poética beuysiana, pues se ponen en juego 
resonancias simbólicas como la capacidad transmisora de la miel y su relación con el trabajo de las abejas y la fertilidad de las flores. Es lo que nos interesa aquí: esta migración de sentido se produce por el montage y las propias características del material utilizado, pues la miel ¿conserva y transmite el significado de las fotografías expuestas o, poco a poco, lo ablanda y destruye para que lo olvidemos, sumidos en la ilusión del progreso? ¿Pueden los documentos cambiar de forma y migrar de sentido a lo largo del tiempo? Como aproximación a estas cuestiones, proponemos una cita del artista italiano Giuseppe Penone: «es la corta duración de nuestra existencia la que hace que llamemos «duro» o «blando» a este u otro material. El tiempo echa a perder esos criterios» (cit. en Didi-Huberman, Ser cráneo 52).

\section{CONCLUSIONES}

Las hipótesis que han guiado nuestro trabajo, como expusimos en la introducción, son dos: que la historia (como hacer científico) y el arte son prácticas que reorganizan o reconfiguran el pasado y el presente de manera diferente, pero con ciertas concomitancias entre ellas (la utilización de documentos, el tratamiento del tiempo y las formas de entender el continuum entre pasado y presente); y que el trabajo artístico, a partir de la incorporación de los conceptos de documento y archivo, resignifica la relación entre historia, cultura y política. A través del estudio de caso de Eduardo Molinari hemos tratado de abrir una línea de análisis y reflexión sobre estos temas.

A lo largo de este artículo hemos definido y conceptualizado el uso del documento y el archivo en la obra de Molinari, y hemos planteado y delimitado una serie de ideas acerca de la intervención sociopolítica a través de la práctica artística: si entendemos la política como la reconfiguración de lo sensible, el arte resignifica material y simbólicamente territorios mediante la construcción de nuevos espacios y relaciones; esto, como venimos planteando, artistas como Eduardo Molinari lo hacen a través de la incorporación de documentos en las obras y a través del montage, en estrecha relación con la historia, entendida esta como espacio de construcción.

No debemos olvidar, sin embargo, que nuestro acercamiento a la producción de Molinari no tiene una pretensión holística, ya que hemos abordado únicamente algunos aspectos de su práctica relacionados con nuestras hipótesis de partida. Estos aspectos son, de todas formas, esenciales para el argentino, tanto en sus reflexiones más teóricas como durante su proceso de creación (hemos señalado, de hecho, que su práctica artística sufrió varios quiebres relacionados con la introducción de la historia, los documentos y los archivos en su producción); luego pensamos que la propia práctica de Molinari demandaba un análisis en esta dirección.

El presente trabajo, por tanto, avanza en esta línea planteando una serie de conceptos o ideas-fuerza fundamentales. Comenzamos definiendo la política, según Rancière, como la reconfiguración de lo sensible, pues introduce sujetos y objetos nuevos y hace visible aquello que no lo era; encontramos que esta definición se acer- 
caba a lo que la práctica artística construye: espacios y relaciones que resignifican material y simbólicamente territorios comunes. Estos planteamientos acerca de la relación entre política y arte están, por un lado, relacionados con nuestras hipótesis de partida y, por otro, con la toma de posición política que Molinari asume en sus obras.

A continuación abordamos dos conceptos, archivo y documento, cada vez más incorporados (apropiados, agenciados) al arte contemporáneo. Por su parte, esta incorporación es, como veíamos, una de las concomitancias que guardan historia y arte como formas de reorganización del pasado y el presente, y Molinari es ejemplo de esta práctica particular.

A través del análisis del corpus observamos que la utilización de documentos y la incorporación de la cultura de archivo a las prácticas artísticas potencian la fragmentación de las temporalidades que configuran las obras en una serie de presentes perpetuos, "congelados» en documentos, mostrando el tiempo como un entretejido de nudos, es decir, como heterocronías.

La utilización de documentos en el arte nos llevó, por supuesto, a abordar el campo de la historia en este trabajo: la historia como espacio de construcción (no como objeto científico), teniendo en cuenta fundamentalmente tres de sus aspectos esenciales: tiempo, memoria y narrativas. Además, sabemos que Molinari comenzó a investigar en archivos e incorporar documentos en sus obras desde el momento en que tomó la decisión de introducir la historia y la memoria en su práctica artística. Esta idea-fuerza de la historia como espacio de construcción abre una línea de investigación (tal vez varias) muy amplia, relacionada, por descontado, con el resto de los conceptos que han articulado nuestro estudio; asimismo, esta idea-fuerza nos planteó una pregunta fundamental que deberemos tratar de responder en un futuro: ¿qué tipo de memoria o historia desencadena el «Archivo Caminante» de Molinari (y, en general, las obras de artistas que incorporan documentos y lógicas de archivo) distinta a la de los archivos y las narrativas oficiales?

Esta cuestión, a su vez, nos remite a otros interrogantes surgidos a lo largo del proceso de investigación y escritura de este artículo, y que deberemos abordar también más adelante: en primer lugar, definir cuál es el alcance de la cultura de archivo, y si la profusión de la lógica archivística en el arte contemporáneo se debe a la tendencia de nuestra cultura a construir la realidad mediante su análisis, gestión, representación y control. En segundo lugar, deberemos analizar qué mecanismos funcionan en el interior de las obras de arte tras la incorporación de documentos: ¿conserva el documento, una vez agenciado por el montage artístico, la «objetividad» que lo caracteriza?, ¿cómo se define una obra de arte hecha a partir de documentos?, ¿cómo operan las diferentes temporalidades puestas en juego en este tipo de creaciones?

Las dos últimas ideas-fuerza se referían a la práctica y técnicas artísticas utilizadas por Eduardo Molinari: collage y montage. Nos ha interesado especialmente esta última pues, a través del ensamblaje de materiales heterogéneos, nos acerca la realidad sensible al mismo tiempo que expone los artificios que la configuran, ya que 
los elementos que conforman un montage han sido sacados de su espacio habitual y migran de una temporalidad a otra, subrayando las rupturas y discontinuidades existentes y haciendo visibles las costuras que articulan las obras. Por tanto, sostenemos que el montage es una técnica adecuada para construir obras que contengan documentos, puesto que crea adjunciones nuevas entre órdenes de realidad, sin dejar de remitir a los elementos originales y a sus significados (y esto, pensamos, acaba por desarticular la percepción habitual de las relaciones entre las cosas o las situaciones).

\section{REFERENCIAS}

Adorno, Theodor W. Teoría estética. Obra completa, 7. Madrid: Akal, 2004. Medio impreso. Benjamin, Walter. Estética y política. Buenos Aires: Las Cuarenta, 2009. Medio impreso. Berardi, Franco. Generación post-alfa. Patologías e imaginarios en el semiocapitalismo. Buenos Aires: Tinta Limón, 2007. Medio impreso.

Bradley, Walter y Charles Esche. Art and social change. A critical reader. London: Tate Publishing, 2007. Medio impreso.

Cabrera, Miguel Ángel. «Hayden White y la teoría del conocimiento histórico. Una aproximación crítica». Pasado y Memoria. Revista de Historia Contemporánea 4 (2005). Medio impreso.

De Certau, Michel. La escritura de la historia. México: UIA-Iteso, 1993. Medio impreso.

De Landa, Manuel. A thousand years of nonlinear history. Nueva York: Zone Books, 1997. Medio impreso.

Deleuze, Gilles. Diferencia y repetición. Buenos Aires: Amorrortu, 2002. Medio impreso.

Deleuze, Gilles y Felix Guattari. Mil mesetas. Capitalismo y esquizofrenia. Valencia: Pre-Textos, 1994. Medio impreso.

Didi-Huberman, Georges. Cuando las imágenes toman posición. Madrid: Antonio Machado Libros, 2008. Medio impreso.

---. Ser cráneo. Madrid: Cuatro Ediciones, 2009. Medio impreso.

Evans, David, ed. Appropiation. London-Cambridge: Whitechapel-MIT Press, 2009. Medio impreso.

Hernández-Navarro, Miguel Ángel, comp. Heterocronías. Tiempo, arte y arqueologías del presente. Murica: Cendeac, 2008. Medio impreso.

Le Goff, Jacques. El orden de la memoria. El tiempo como imaginario. Barcelona: Paidós, 1991. Medio impreso.

Lyotard, Jean-François. La condición postmoderna. Madrid: Cátedra, 2008. Medio impreso. Mate, Manuel-Reyes. La herencia del olvido. Madrid: Errata Naturae, 2008. Medio impreso. Molinari, Eduardo. El cuchillo (texto de la exposición). Buenos Aires, 2000. Documento informático facilitado por el artista.

---. Tras los pasos de los hombres de maíz. Chemnitz: autoedición, 2008. Medio impreso.

---. Los niños de la soja. Buenos Aires: autoedición, 2010. Medio impreso. 
---. «Presentación personal. ¿Pueden las mulas cruzar las aguas?». Seminario Narrativas de Fuga III. UNIA, Sevilla, 14 de mayo de 2010. Documento informático facilitado por el artista.

Mignolo, Walter y Elizabeth Boone, eds. Writing without words. Alternative literacies in Mesoamerica and the Andes. Durham: Duke University Press, 1994. Medio impreso.

Ortega, María Luisa. «De la certeza a la incertidumbre: collage, documental y discurso político en América Latina». Piedra, papel y tijera. El collage en el cine documental. Eds. Sonia García y Laura Gómez. Madrid: Ocho y Medio Libros de Cine, 2009. Medio impreso.

Rancière, Jacques. Sobre políticas estéticas. Barcelona: Universitat Autònoma de Barcelona, 2005. Medio impreso.

Ricoeur, Paul. La memoria, la historia, el olvido. Madrid: Trotta, 2003. Medio impreso.

---. «Historia y memoria. La escritura de la historia y la representación del pasado». Historizar el pasado vivo en América Latina. Dir. Anne Pérotin-Dumon. Santiago: Universidad Alberto Hurtado, 2007. «http://goo.gl/7v2e0». Sitio web.

Rosón, María. «El archivo de la guerra: construcciones para la memoria». Vivencia y memoria de la Guerra de la Independencia en la Fundación Lázaro Galdiano. Madrid: Fundación Lázaro Galdiano y Sociedad Estatal de Conmemoraciones Culturales, 2008. Medio impreso.

Traverso, Enzo. El pasado, instrucciones de uso. Historia, memoria, política. Madrid: Marcial Pons, 2007. Medio impreso. 